\title{
O Isomorfismo na Educação Ambiental como Tema Transversal em Programas de Graduação em AdministraçÃo
}

\author{
The Isomorphism in Environmental Education as a Cross-Cutting
}

Theme in Undergraduate Management Programs

Heloísa Helena Marques da Silva

Assistente Acadêmica do PPGA das Faculdades Metropolitanas Unidas - FMU - São Paulo - SP - Brasil. E-mail: hheloiza@gmail.com

Milton de Abreu Campanario

Doutorado em Doctor of Philosophy pela Cornell University, EUA. Professor de Economia da Faculdade de Economia, Administração e Contabilidade - USP - São Paulo - SP - Brasil.E-mail: campanario@usp.br

Maria Tereza Saraiva de Souza

Doutorado em Administração de Empresas pela Escola de Administração de Empresas de São Paulo. Professora de PPGA da FEI Centro Universitário da FEI - São Paulo - SP - Brasil.E-mail: mariaterezasaraivas@gmail.com

\section{Resumo}

A Política Nacional de Educação Ambiental determina a inclusão da Educação Ambiental em todos os níveis do ensino de modo transversal e contínuo, vedando sua utilização como disciplina específica. O referencial teórico está assentado no isomorfismo aplicado ao tema da transversalidade em Instituições de Ensino Superior (IES), buscando identificar os mecanismos que as impulsionam a mudar de comportamento frente a essa regulamentação, desvendando quais forças promovem a incorporação da educação ambiental na grade da graduação em Administração, como tema transversal. A metodologia utilizada é quantitativoqualitativa e utiliza um estudo multicaso junto a quatro IES, com Graduação em Administração. Conclui-se que pressão isomórfica coercitiva, por parte da sociedade, e normativa, ligada à atuação profissional, são as que mais contribuem para a institucionalização da educação ambiental na grade curricular. As demandas sociais para formação do administrador com conhecimentos ambientais é o fator mais forte neste processo.

Palavras-chave: Educação Ambiental. Graduação em Administração. Tema Transversal. Sustentabilidade. Isomorfismo.

\section{Abstract}

The National Environmental Education Policy determines the inclusion of environmental education at all levels of education as a continuous cross-cutting model, prohibiting its use as a specific discipline. The theoretical perspective is based on isomorphism applied to the transverse mode in Higher Education Institutions - HEI, seeking to identify the mechanisms that drive the change of their behavior, uncovering what forces promote the incorporation of environmental education in the disciplines as a crosscutting theme. The methodology used is quantitative-qualitative and uses a case study at four HEIs with Degree in Administration. We conclude that coercive isomorphic pressure, by society, and rules, linked to professional practice, contribute mostly to the institutionalization of environmental education in the curriculum. Social demands for training the administrator with environmental knowledge is the strongest factor in this process.

Keywords: Environmental Education. Undergraduate in Management. Cross-cutting Theme. Sustainability. Isomorphism. 


\section{INTRODUÇÃO}

Primeiramente, ressalta-se que este trabalho recebeu apoio financeiro do Programa Pró-Administração da CAPES.

No Brasil, em 1999, foi criada a Política Nacional de Educação Ambiental, sancionada pela Lei n. 9.795 e regulamentada pelo Decreto n. 4.281/02 (BRASIL, 1999; 2002), determinando a obrigatoriedade da Educação Ambiental (EA) como tema transversal em todos os níveis educacionais. A Política Nacional de Educação Ambiental (PNEA) estabelece para as Instituições de Ensino, públicas e privadas, a responsabilidade de integrar a dimensão ambiental em seus cursos $e$ de capacitar os docentes para abordar a Educação Ambiental como tema transversal. Dessa forma, há a necessidade de alterações nas estruturas curriculares de todos os cursos de graduação, incluindo Administração. Nesses cursos, as IES devem fazer uma adequação que integre a EA nas disciplinas convencionais de modo transversal, contínuo e permanente (BRASIL, 2002). Kluglianskas (1993) defende o fator "meio ambiente" como quesito importante para a eficácia das organizações e propõe sua inclusão nos cursos de graduação. Para esse autor, a interdisciplinaridade que caracteriza essa temática ambiental implica no abandono das abordagens tradicionais. Para Gonçalves et al. (2009), os desafios para a integração da temática ambiental nos cursos de graduação serão superados na medida em que for tratada com consistência pelos projetos pedagógicos dos cursos.

Barbieri (2004), ao propor a gestão ambiental no curso de graduação, percebe a relação meio-ambiente-desenvolvimento como o ponto central de Educaçõ Ambiental (EA) e aponta como problemático o lento desenvolvimento das abordagens multidisciplinar $e$ interdisciplinar no âmbito das disciplinas de Administração. Barbieri e Silva (2010) propõem a disciplina de gestão ambiental como forma de colocar as questões ambientais em pauta no curso de Administração $e$ pontuam a falta de conhecimento dos professores para tratar da EA transversalmente como uma das dificuldades para implantação da PNEA. Esses autores passam a ver a gestão ambiental como um conjunto de temas que podem ser desenvolvidos transversalmente no curso de graduação, dentro de uma perspectiva em que a EA e a gestão ambiental compartilhem pontos comuns. (BARBIERI; SILVA, 2011)

A EA é pouco abordada pela área da Administração. Isso pode ser verificado em dois estudos realizados por Souza et al. (2011a; 2011b). Foi feito, inicialmente, um mapeamento da produção científica sobre sustentabilidade ambiental dos cursos de senso estrito entre 1987 e 2009 e foram encontradas 13.656 teses e dissertações. Dentre elas, 536 estão trabalhos relacionados à sustentabilidade ambiental. Foi possível mapear nove trabalhos sobre EA, verificando-se que nenhum deles utiliza essa temática como tópico transversal em cursos de administração. Em outro estudo, realizado em periódicos A1, A2 e B1 nacionais na área de Administração, Souza et al. (2011b) verificaram que houve um aumento substancial de artigos sobre sustentabilidade ambiental. Foram encontrados 212 artigos sobre a temática investigada. Entre eles, apenas dois artigos contextualizando a EA no curso de graduação em Administração (BARBIERI, 2004; GONÇALVES-DIAS et al., 2009). Nesse contexto, o objetivo geral desta pesquisa consiste em responder às seguintes questões: Quais são as pressões que contribuem para a institucionalização da Educação Ambiental em cursos de graduação em Administração como tema transversal, conforme determina a PNEA? Existem pressões isomórficas que poderiam facilitar a convergência e a articulação do ensino ambiental como tema transversal? Ao buscar responder às questões de pesquisa por meio de método de pesquisa quantitativo-qualitativa a ser aplicado em instituições de ensino, este estudo busca atingir seis objetivos específicos: a) analisar como o Ministério da Educação supervisiona a implantação da PNEA no curso de graduação em Administração; b) avaliar como as IES incorporam conteúdos relacionados às temáticas sobre sustentabilidade nestes cursos; c) identificar quais pressões isomórficas motivaram a inserção da temática sobre sustentabilidade; d) verificar se a formação inicial do docente é geradora de pressão normativa ao contemplar temas relacionados à sustentabilidade, EA ou tema transversal; e) examinar se os docentes foram capacitados para realizar a inserção das temáticas sobre sustentabilidade ao ministrarem a disciplina e identificar os responsáveis por essa formação; e f) observar quais metodologias e quais temas os professores utilizam para a inserção das 
temáticas sobre sustentabilidade como tema transversal ao ministrarem a disciplina. Este trabalho divide-se em cinco partes: introdução, fundamentação teórica, método de pesquisa, análise e discussão dos resultados e considerações finais.

\section{Referencial Teórico e Temático}

Este referencial busca analisar quatro grandes vertentes que direcionam a pesquisa: o isomorfismo institucional como teoria que auxilia entender as mudanças organizacionais, a Política Nacional de Ensino Ambiental e como temática central no sistema educacional brasileiro, as Diretrizes Curriculares Nacionais do Curso de Administração que buscam aperfeiçoar a formação do profissional e a temática da transversalidade como opção didática. Esse conjunto de referências forma o que se designa como Modelo Conceitual de Análise, parte derradeira deste referencial.

\subsection{Isomorfismo Institucional}

Os mecanismos que impulsionam as organizações para a mudança são nomeados de pressões isomórficas (DIMAGGIO; POWELL, 2005). O isomorfismo é um processo de restrição que obriga uma unidade da população a assemelhar-se a outras unidades que enfrentam o mesmo conjunto de condições ambientais. Os fatores isomórficos pressionam a organização a se parecer a outras no mesmo conjunto de condições ambientais (ROSSETO; ROSSETO, 2005). Existem dois tipos de isomorfismo: o competitivo e o institucional. $\mathrm{O}$ competitivo enfatiza apenas competição no mercado. $\mathrm{O}$ institucional induz as organizações ao poder político, à adequação social e econômica e legitimação institucional. Os processos isomórficos provocam as mudanças nas organizações para o alcance da legitimidade e estabilidade. (FREITAS; GUIMARÃES, 2007; GINN; SHEN; MOSELEY, 2008)

Dimaggio e Powell (2005) propõem três mecanismos de mudanças isomórficas institucionais: isomorfismo coercitivo, resultante de influencias políticas e de demandas ligadas à legitimidade; isomorfismo miméti$\mathrm{co}$, que deriva de respostas padronizadas à incerteza; isomorfismo normativo, associado à profissionalização. $\mathrm{O}$ isomorfismo coercitivo pode resultar de pressões formais e informais que são exercidas por outras organizações, podendo ser sentidas como coerção, persuasão, ou conluio (DIMAGGIO; POWELL, 2005 p. 77). Segundo Venard e Hanafi (2008), as pressões coercitivas podem ser um fator-chave para explicar a adoção, por exemplo, da corrupção por uma instituição, ou o seu oposto, condutas éticas. A mudança organizacional provocada pelo isomorfismo coercitivo pode ser uma resposta a leis governamentais ou exigências contratuais (DIMAGGIO; POWELL, 2005; LACOMBE; CHU, 2008). Há peculiaridades do isomorfismo quando os ambientes são politicamente construídos. Tomadores de decisão não experimentam as consequências de suas ações políticas, tornando as organizações cada vez mais homogêneas dentro de determinados domínios. (DIMAGGIO; POWELL, 2005, p. 78)

No isomorfismo mimético a incerteza é uma força poderosa que encoraja a imitação. As organizações tomam outras como modelo quando, por exemplo, as tecnologias organizacionais são insuficientemente compreendidas, as metas são ambíguas e o ambiente cria uma incerteza simbólica. O mimetismo pode provocar uma considerável economia em ações humanas, quando uma organização tem à sua frente um problema com causas ambíguas e soluções pouco nítidas (DIMAGGIO; POWELL, 2005; TOLBERT; ZUCKER, 1999). Ao imitar, a organização pode criar uma base que lhe permita atingir novos campos de atuação, já alcançados por suas concorrentes com maior potencial econômico. (BROUTHERS; O'DONNELL; HADJIMARCOU, 2005). A organização que sofre a imitação pode não ter consciência que está sendo (e nem desejar ser) imitada.

A profissionalização é a principal fonte geradora do isomorfismo normativo. Dimaggio e Powell (2005) interpretam a profissionalização como a luta coletiva dos membros de uma profissão para definir os métodos e as condições do seu trabalho, para controlar a produção e estabelecer uma base cognitiva de legitimação para a autonomia da sua profissão. As categorias profissionais estão sujeitas às mesmas forças coercitivas e miméticas que pressionam as organizações. As universidades, as instituições de treinamento profissional e as associações profissionais constituem importantes centros de desenvolvimento de normas para o comportamento organizacional entre os gerentes profissionais e seus funcionários. (MACHADO-DA-SILVA; 
COSER, 2006; LACOMBE; CHU, 2008; CORAIOLA; MACHADO-DA-SILVA, 2008)

\subsection{Política Nacional de Educação Ambiental (PNEA)}

A Lei n. 9.795/99 cria a PNEA, traçando objetivos para EA. A sua regulamentação é formalizada dois anos depois pelo Decreto n. 4.281/02, que define seu Órgão Gestor, dirigido pelos Ministros do Meio Ambiente e da Educação (BRASIL, 1999, 2002). No emaranhado normativo sobre o tema, destaca-se a Lei n. 9.795/99, formada por quatro capítulos (BRASIL, 1999). No capítulo I, encontra-se a definição de EA: "[...] processos por meio dos quais o indivíduo e a coletividade constroem valores sociais, conhecimentos, habilidades, atitudes e competências voltadas para a conservação do meio ambiente" (BRASIL, 1999, art. $\left.1^{\circ}\right)$. A Lei determina que a EA é um componente essencial e permanente da educação nacional, sendo sua presença obrigatória em todos o níveis e modalidades do processo educativo (BRASIL, 1999, art. $2^{\circ}$ ). Essa Lei define a EA como um direito de todo cidadão e distribui responsabilidades: o Poder Público deve promover a dimensão ambiental em todos os níveis do ensino $e$ as instituições educacionais públicas $e$ privadas são responsáveis por promover o EA.

$\mathrm{O}$ artigo $5^{\circ}$ da Lei estabelece os objetivos para a EA. Segundo Winther (2010, p. 40), o artigo mostra "[...] o caráter transversal da EA com relação às disciplinas tradicionais do currículo escolar [...]", afirmando-a como uma política voltada para a construção de uma sociedade ambientalmente sustentável. $\mathrm{O}$ artigo $8^{\circ}$ relaciona as linhas de atuação pelas quais devem seguir as atividades vinculadas ao PNEA: capacitação de recursos humanos; desenvolvimento de estudos, pesquisas e experimentações; produção e divulgação de material educativo; e acompanhamento e avaliação. Dentre as linhas de atuação citadas no artigo $8^{\circ}$ destaca-se, no Parágrafo $2^{\circ}$, a incorporação da dimensão ambiental na formação, especialização $e$ atualização dos educadores de todos os níveis e modalidades de ensino. Entende-se por EA como aquela presente no âmbito dos currículos das instituições, públicas e privadas, englobando: educação básica; educação infantil; ensino fundamental e ensino médio; educação superior; educação especial; educação profissional; $e$ educação de jovens e adultos (BRASIL, 1999, art. $9^{\circ}$ ). $\mathrm{O}$ artigo 10 esclarece que a EA deve ser desenvolvida como uma prática educativa integrada, contínua e permanente em todos os níveis e modalidades do ensino formal e que não deve ser implantada como disciplina específica no currículo de ensino, facultando essa liberdade apenas para os cursos de pós-graduação, extensão e nas áreas voltadas para os aspectos metodológicos de EA (BRASIL, 1999). O artigo 11 determina que a dimensão ambiental deve constar do currículo de formação de professores de todos os níveis e em todas as disciplinas e que os professores em exercício devem receber formação complementar em suas áreas de atuação (CARVALHO, 2003). Coloca-se o desafio de propor sequências didáticas e questões conceituais e metodológicas de ensino que utiliza (TRIVELATO, 2003). Segundo o artigo $12^{\circ}$, a autorização e supervisão do funcionamento de instituições de ensino $e$ de seus cursos, nas redes pública e privada, devem observar o disposto na Lei n. 9.795/99 (BRASIL, 1999), podendo-se concluir que as autorizações para o funcionamento dos cursos oferecidos pelas Instituições de Ensino de todos os níveis ficam vinculadas ao uso da EA como uma prática educativa, portanto, não devendo ser implantada como disciplina específica. A regulamentação da PNEA entrou em vigor em 25 de junho de 2002, por meio do Decreto n. 4.281 (BRASIL, 2002). $\mathrm{O}$ artigo $3^{\circ}$ enumera as competências do Órgão Gestor, com destaque para: "[...] apoiar o processo de implementação e avaliação da Política Nacional de Educação Ambiental em todos os níveis, delegando competências quando necessário" (art. $3^{\circ}$, incisos III). Fica sob o Ministério da Educação a responsabilidade de apoiar a inclusão da EA em todos os níveis educacionais, por intermédio de seus órgãos competentes. $\mathrm{O}$ artigo $5^{\circ}$ estabelece que a integração da EA às disciplinas deve ocorrer de modo transversal, contínuo e permanente, e a adequação dos programas já vigentes de formação continuada de educadores (art. $5^{\circ}$, incisos I - II).

O Decreto n. 4.281/02 deixa claro que a integração da EA deve acontecer de um modo transversal, confirmando que as Diretrizes Curriculares Nacionais (DCN) e os Parâmetros Curriculares Nacionais (PCN) devem ser usados para a inclusão contínua e permanente da EA, solicitando a adequação dos programas de formação continuada ministrada aos docentes. 
A formação continuada é concomitante ao exercício profissional e proporciona a aquisição de novos conhecimentos, atitudes e competências ligadas às necessidades da docência. (GARCIA,1992)

\subsection{Diretrizes Curriculares Nacionais do Curso de Administração}

As atuais regras da DCN foram retificadas pela Resolução n. 4, de 13 julho de 2005. Segundo a Resolução n. 4/05, toda IES que oferece cursos de Graduação em Administração e bacharelado deve utilizar a DCN para organização curricular do curso (BRASIL, 2005, art. $1^{\circ}$ ). Essa organização fica expressa por intermédio do projeto pedagógico que abrange: o perfil do formando; as competências e habilidades; os componentes curriculares (disciplinas); o estágio curricular supervisionado; as atividades complementares; o sistema de avaliação; o projeto de iniciação científica ou o projeto de atividade, como Trabalho de Curso; e do regime de acadêmico de oferta e outros aspectos que tornem consistente o projeto pedagógico (art. $2^{\circ}$ ). As competências e habilidades que devem ser proporcionadas pelo curso de graduação, ao administrador, são descritas no artigo $4^{\circ}$ e no artigo $5^{\circ}$, com os conteúdos desejados nos projetos pedagógicos, que devem revelar inter-relações com a realidade nacional $e$ internacional, segundo uma perspectiva histórica $e$ contextualizada de sua aplicabilidade no âmbito das organizações. Destaca-se também a presença dos Conteúdos de Formação Complementar: estudos opcionais de caráter transversal e interdisciplinar para o enriquecimento do perfil do formando. (BRASIL, 2005, art. $5^{\circ}$, inciso IV, grifo nosso)

Nas DCN da Administração, os conteúdos com caráter transversal e interdisciplinar, onde deve estar contida a EA, são reconhecidos como itens para o enriquecimento do perfil do formando. Nota-se uma falta de definição específica desses conteúdos e de uma ligação com as determinações da Lei n. 9.794/99 (BRASIL, 1999). Situação diversa é precebida nos Parâmetros Curriculares Nacionais (PCN), onde se encontra uma clara definição de quais são temas transversais que devem ser desenvolvidos pelas Instituições de Ensino Médio e Fundamental - "Ética, Saúde, Meio Ambiente, Pluralidade Cultural e Orientação Sexual”, com seu objetivo pedagógico e sua concepção de aplicação pelas áreas ou disciplinas. (MEC, 1997, p. 44-45, 71)
As atividades complementares são abordadas, no artigo $8^{\circ}$, como "[...] componentes curriculares que possibilitam o reconhecimento, por avaliação, de habilidades, conhecimentos e competências do aluno [...]", que podem ser adquiridas fora do ambiente escolar, incluindo-se a "[...] pratica de estudos e atividades independentes, transversais, opcionais, de interdisciplinaridade [...]", que sejam relacionadas com o ambiente do trabalho e com ações de extensão realizada junto à comunidade (BRASIL, 2005, art. 8). Na observação atenta desse artigo, onde se cita a prática de estudos e atividades transversais, onde estaria inserida a EA, a categorização como atividade opcional vai de encontro às orientações da PNEA, que determina a EA como uma prática que deve ser integrada à disciplina.

\subsection{Tema Transversal e as Metodologias para sua Aplicação}

A transversalidade $e$ a interdisciplinaridade fundamentam-se contra uma concepção de conhecimento que analisa a realidade como um conjunto de dados estanques e observados a partir da isenção do distanciamento. As duas consideram a importância da complexidade do mundo real e sua teia de relações com seus aspectos diferentes e contraditórios. Ao mesmo tempo, as duas diferem: "[...] a interdisciplinaridade refere-se a uma abordagem epistemológica dos objetos de conhecimento e a transversalidade diz respeito principalmente à dimensão da didática". (MEC, 1997 p. 31)

Para Nicolescu (1999), a transversalidade relaciona-se com tudo aquilo que está ao mesmo tempo entre, através e além das diferentes disciplinas, tendo como objetivo a compreensão do mundo presente. Segundo Araújo (2003b), seus princípios nascem do questionamento sobre a falta de contextualização da ciência e da cultura ao não tratarem de temas que digam respeito aos interesses da maioria das pessoas. Os temas transversais envolvem temas que tratam de processos vividos pela sociedade em seu cotidiano. Interdisciplinaridade e transversalidade alimentam-se mutuamente, pois para trabalhar os temas transversais adequadamente não se pode ter uma perspectiva disciplinar rígida (ZABALLA; FAZENDA, 2002 apud AMBONI et al., 2010, p. 6). De fato, o conceito de transversalidade "[...] refere-se a um tipo de ensino que deve estar presente na educação obrigatória, não como unidade didática isolada, mas como eixos 
fundamentais dos objetivos, conteúdos e princípios [...]" que protejam as conexões de matérias clássicas, acrescentando contextos sociais dinâmicos. (BARBIERI; SILVA, 2011 p. 150)

Moreno (2003), em sua proposta radical de reforma do ensino espanhol, defende que os temas transversais sejam o eixo longitudinal. Em volta deles devem girar a temáticas curriculares. Outra forma de conceber a transversalidade é entender que os conteú- dos tradicionais formam o eixo longitudinal do sistema educacional. Em volta dessas áreas do conhecimento devem circular ou perpassar os temas transversais. As disciplinas são o eixo condutor do currículo longitudinal e os temas formam o eixo transversal, ligados ao cotidiano da sociedade (ARAÚJO, 2003a, 2003b). A Figura 1 demonstra uma imagem gráfica que representa a concepção apresentada e a aplicação da transversalidade conforme entendida no PCN.
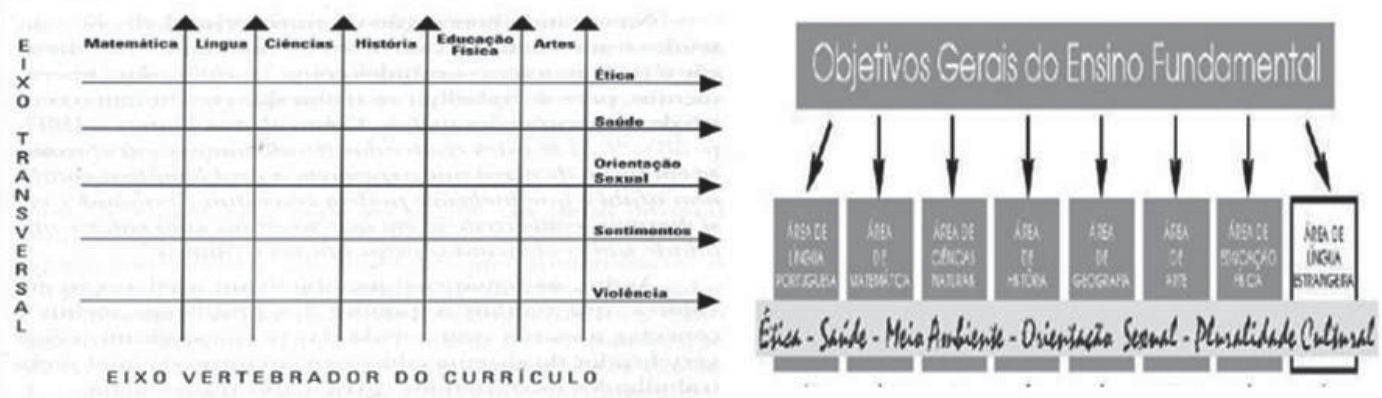

Figura 1: Concepção de transversalidade e aplicação da transversalidade

Fonte: Araújo ((2003.b, p. 57) e MEC ( 1997 p. 7) - recorte

Na comparação da concepção apresentada por Araújo (2003b) com aquele proposto pelo PCN para a aplicação da transversalidade no ensino fundamental (MEC, 1997), percebe-se uma similaridade entre as concepções. Araújo (2003b) representa cada tema por linhas independentes. Os PCNs (MEC, 1997) as integram em uma única linha, que corta transversalmente as disciplinas do curso. Nessa visão oficial do MEC, os temas transversais têm o objetivo de envolver as dis- ciplinas, trazendo para o curso assuntos relacionados à realidade social. Segundo Araújo (2003b), os temas transversais podem ser aplicados com cinco formas metodológicas: Atividades Pontuais; Disciplinas, Palestras e Assessoria; Projetos Interdisciplinares; Transversalidade Incorporada na Disciplina; e Transversalidade como Currículo Oculto. No Quadro 1 a definição de cada forma metodológica.

\begin{tabular}{|c|c|}
\hline Metodologia & DefinIÇÃo \\
\hline AP - Atividades Pontuais & $\begin{array}{l}\text { A transversalidade ocorre no conteúdo da disciplina de forma pontual, por intermédio de trabalhos, módulos } \\
\text { de atividades ou aulas específicas. }\end{array}$ \\
\hline $\begin{array}{l}\text { DPA - Disciplinas, } \\
\text { Palestras e Assessorias }\end{array}$ & $\begin{array}{l}\text { O professor não possuiria a formação adequada para tratar o tema transversal na sala de aula e recorre a } \\
\text { profissionais especializados para seu oferecimento por meio de disciplinas extras, palestras e pelo desenvolvimento } \\
\text { de projetos que estão desconectados das atividades desenvolvidas pelas disciplinas curriculares. }\end{array}$ \\
\hline $\begin{array}{l}\text { PI - } \\
\text { Inter }\end{array}$ & as disciplinas \\
\hline $\begin{array}{l}\text { TID - Transversalidade } \\
\text { Incorporada nas } \\
\text { Disciplinas }\end{array}$ & $\begin{array}{l}\text { É uma forma de incorporar o tema transversal aos conteúdos disciplinares. As preocupações com o cotidiano e } \\
\text { os problemas sociais estão intrinsecamente ligados aos objetivos das disciplinas específicas. O comprometimento } \\
\text { do professor com o tema transversal tem influência direta nessa forma metodológica. }\end{array}$ \\
\hline $\begin{array}{l}\text { TCO - Transversalidade } \\
\text { Como Currículo Oculto }\end{array}$ & $\begin{array}{l}\text { A presença do tema transversal é um "currículo oculto" que permeia as ações e avaliações dos docentes. O } \\
\text { uso das temáticas que ocorre no surgimento de oportunidades nas salas de aula. Que o professor usa para } \\
\text { promover discussões com os alunos sobre o ocorrido e suas consequências. }\end{array}$ \\
\hline
\end{tabular}

Quadro 1: Formas para aplicação de um tema transversal

Nota: Definições tiradas de Araújo (2003b) 
Todas as formas citadas não são excludentes entre si, podendo ser usadas de forma complementar e acontecerem simultaneamente durante a disciplina e no curso.

\subsection{Desenvolvimento do Modelo Conceitual de Análise}

Nesse item serão desenvolvidos os modelos que norteiam as atividades de análise utilizadas nesse trabalho. A integração do tema transversal do PCN (MEC, 1997) com as formas metodológicas apresentadas por Araújo (2003b) e os conteúdos de formação profissional das Diretrizes Curriculares Nacionais do Curso de Administração (BRASIL, 2005) formam a base para a construção de um modelo conceitual de um tema transversal na Graduação em Administração, conforme ilustrado na Figura 2.

Na Figura 2, a linha da transversalidade, que corta os conteúdos de formação profissional do curso de Graduação em Administração, é preenchida pelas formas metodológicas de aplicação do tema transversal. Elas se repetem ao perpassarem cada conteúdo de formação. Integrar a Educação Ambiental no curso de graduação em Administração como um tema transversal como determina a PNEA (BRASIL, 1999; 2002) significa: dar relevância ao tema para as organizações, conforme indica as DCN (BRASIL, 2004); impregnar metodologicamente os conteúdos tradicionais ministrados nas disciplinas (ARAÚJO, 2003b); e tornar o tema uma experiência educativa que contribua para o alcance de uma sociedade sustentável. A EA adaptada à realidade e às necessidades do curso de Graduação em Administração seria abordar como tema transversal a produção científica sobre sustentabilidade em seus aspectos múltiplos produzida pela Administração como área do conhecimento, que comporia a linha da transversalidade que corta os conteúdos de formação profissional.

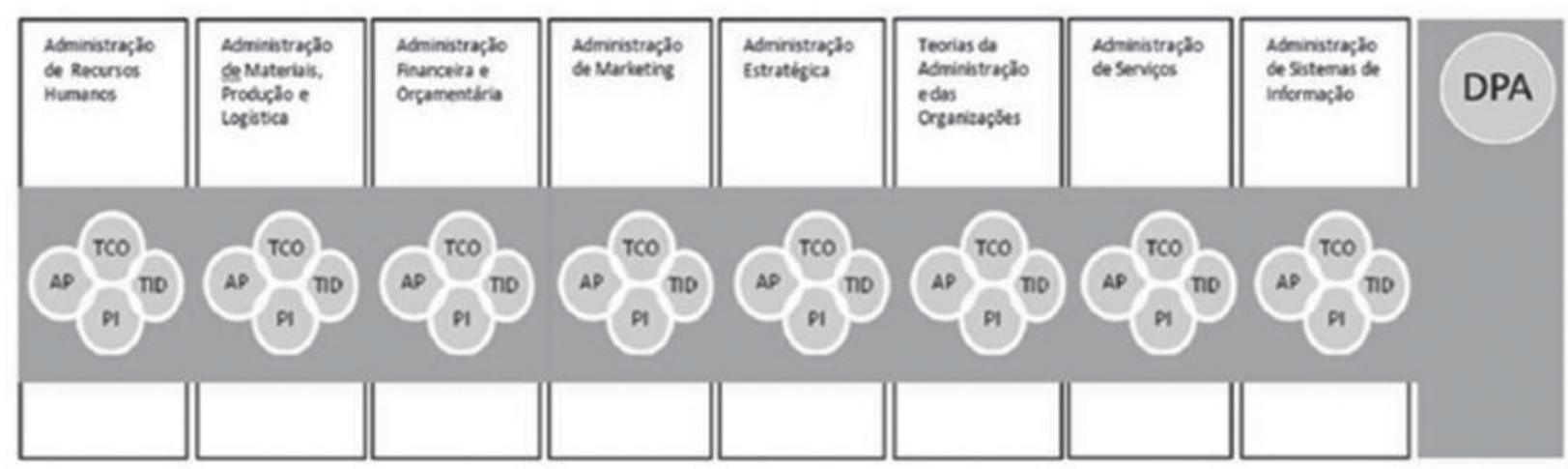

Figura 2 Formas de aplicação do tema transversal no curso de Administração Fonte: Adaptado de MEC (1997 p. 71), Araújo (2003b) e DCN Brasil (2005)

A produção científica comporia a linha da transversalidade que corta os conteúdos de formação profissional, com destaque para as suas formas metodológicas de aplicação de um tema transversal.
O Quadro 2 apresenta a união da relação de aderência feita por Barbieri e Silva (2010; 2011) e algumas das temáticas ambientais levantadas por Souza et al. (2011a; 2011b). 


\begin{tabular}{|c|c|c|}
\hline \multirow{2}{*}{$\begin{array}{c}\text { Conteúdos de Formação } \\
\text { Profissional }\end{array}$} & \multicolumn{2}{|c|}{ Temáticas da Produção Cientifica sobre Sustentabilidade } \\
\hline & Temáticas AmBientais & ENGEMA \\
\hline $\begin{array}{l}\text { Administração } \\
\text { Financeira e Orçamentária }\end{array}$ & $\begin{array}{l}\text { Passivo ambiental; } \\
\text { Contabilidade ambiental; } \\
\text { Indicadores de desenvolvimento } \\
\text { Sustentável; } \\
\text { Relatórios de sustentabilidade. }\end{array}$ & $\begin{array}{l}\text { Análise de risco; } \\
\text { Contabilidade ambiental; } \\
\text { Fundos éticos; } \\
\text { Indicadores socioambientais; } \\
\text { Investimentos sustentáveis; } \\
\text { Riscos ambientais e valor da empresa; } \\
\text { Técnica de avaliação e valoração econômica. }\end{array}$ \\
\hline $\begin{array}{l}\text { Teorias da Administração; } \\
\text { Teorias das Organizações; } \\
\text { Administração de Serviços; } \\
\text { Administração Estratégica; } \\
\text { Administração de Sistema de } \\
\text { Informação. }\end{array}$ & $\begin{array}{l}\text { Responsabilidade ambiental; } \\
\text { Gestão de meio ambiente; } \\
\text { Governança ambiental; } \\
\text { Índice de sustentabilidade; } \\
\text { Sustentabilidade corporativa; } \\
\text { Norma socioambiental; } \\
\text { Gestão socioambiental; } \\
\text { Incorporação de questões } \\
\text { ambientais e sociais; } \\
\text { Responsabilidade (social/ } \\
\text { ambiental/socioambiental). }\end{array}$ & $\begin{array}{l}\text { Ecologia industrial; } \\
\text { Gestão socioambiental e de desempenho empresarial; } \\
\text { Gestão sustentável da cadeia de suprimento; } \\
\text { Gestão tecnológica, meio ambiente } \\
\text { e responsabilidade social; } \\
\text { Indicadores ambientais; } \\
\text { Modelos de gestão ambiental estratégica; } \\
\text { Parcerias interorganizacionais e } \\
\text { empreendedorismo socioambiental; } \\
\text { Responsabilidade socioambiental empresarial. }\end{array}$ \\
\hline $\begin{array}{l}\text { Administração de } \\
\text { Recursos Humanos }\end{array}$ & $\begin{array}{l}\text { Conflito (ambiental-socioambiental); } \\
\text { Coleta seletiva; } \\
\text { Educação Ambiental. }\end{array}$ & $\begin{array}{l}\text { Conflitos no âmbito socioambiental empresarial; } \\
\text { Gestão de RH para gestão ambiental; } \\
\text { Sistemas de gestão ambiental e de responsabilidade social; } \\
\text { Técnicas de negociação e mediação } \\
\text { em questões socioambientais. }\end{array}$ \\
\hline $\begin{array}{l}\text { Administração de } \\
\text { Materiais, Produção } \\
\text { e Logística }\end{array}$ & $\begin{array}{l}\text { Ecoeficiência; } \\
\text { Análise de risco ambiental; } \\
\text { Dano ambiental; } \\
\text { Acidente ambiental; } \\
\text { Reaproveitamento, reciclagem; } \\
\text { Gestão de perdas; } \\
\text { Produção mais limpa; } \\
\text { Cadeia de suprimento orgânico } \\
\text { e reversa; } \\
\text { Compra verde; } \\
\text { Logística reversa; } \\
\text { Avaliação do ciclo de vida. }\end{array}$ & $\begin{array}{l}\text { Análise de riscos ambientais; } \\
\text { Avaliação de impactos ambientais; } \\
\text { Avaliação do ciclo de vida; } \\
\text { Compras sustentáveis; } \\
\text { Ecologia industrial; } \\
\text { Estratégia empresarial e meio ambiente; } \\
\text { Gerenciamento integrado de resíduos; } \\
\text { Gestão sustentável de cadeia de suprimento; } \\
\text { Gestão tecnológica, meio ambiente } \\
\text { e responsabilidade social; } \\
\text { Indicadores socioambientais; } \\
\text { Logística reversa; Produção mais limpa; } \\
\text { Redução de pobreza e projetos socioambientais } \\
\text { empresariais; Rotulagem e certificação ambiental; } \\
\text { Sistema de gestão ambiental e responsabilidade } \\
\text { social; Sistemas de gestão integrados. }\end{array}$ \\
\hline $\begin{array}{l}\text { Administração } \\
\text { Mercadológica /Marketing }\end{array}$ & $\begin{array}{l}\text { Análise do Ciclo de vida (ACV); } \\
\text { Apelo/ Atributo (ecológico); } \\
\text { Comportamento socioambiental; } \\
\text { Consumo (consciente, sustentável); } \\
\text { Decisão de compra ecológica; } \\
\text { Marketing ambiental- } \\
\text { Propaganda ecológica; } \\
\text { Produto sustentável. }\end{array}$ & $\begin{array}{l}\text { Avaliação do ciclo de vida; } \\
\text { Consumo sustentável; } \\
\text { Estratégia empresarial e meio ambiente; } \\
\text { Marketing verde e social; } \\
\text { Redução de pobreza e projetos } \\
\text { socioambientais empresariais; } \\
\text { Rotulagem e certificação ambiental. }\end{array}$ \\
\hline
\end{tabular}

Quadro 2: Temáticas - Linha de Transversalidade

Fonte: Adaptado de Souza et al. (2010; 2011) e Barbieri e Silva (2010; 2011) 
Essa abordagem apresenta uma das múltiplas possibilidades de temáticas que poderiam preencher a linha de transversalidade de um curso de graduação em Administração, utilizando as metodologias para aplicação do tema transversal (ARAÚJO, 2003b). A integração da dimensão ambiental no currículo de formação do professor, conforme determina a PNEA (BRASIL, 1999; 2002), vai auxiliar o docente que atua na Administração a adquirir conhecimentos para que possa abordar essa temática de forma transdisciplinar e a integra-la com os distintos campos das disciplinas do curso de Administração (CARVALHO, 2003). O curso de formação continuada ou complementar deve ser concomitante com o exercício profissional, propiciando, a esse docente, novos conhecimentos, atitudes e competências. (GARCIA, 1992)

\section{Método de Pesquisa}

Para atender aos objetivos propostos, realizou-se uma pesquisa com enquadramentos quantitativos $e$ qualitativos. A análise qualitativa é útil para compreensão da lógica das informações, sugerindo, de maneira direta, como podem ser fortalecidas pelo levantamento quantitativo (EISENHARDT, 1989). Para coleta de dados se utilizou: análise documental nos Instrumentos de Avaliação para Renovação de Reconhecimento de Cursos de Graduação do Ministério da Educação; entrevista semiestruturada com os coordenadores; e a aplicação de um questionário junto aos professores.

Em relação aos procedimentos, a presente pesquisa é um estudo multicaso, realizado em quatro IES que oferecem cursos de graduação em Administração no Estado de São Paulo. O estudo de caso é uma estratégia que pode ser usada para explorar as situações em que não haja um único conjunto de resultados para o exame de eventos que apresentem comportamentos relevantes, que não podem ser manipulados (YIN, 2010). O estudo multicaso foi realizado em duas IES privadas e duas IES públicas. A escolha das IES pesquisadas ocorreu após o aceite de quatro instituições entre as dez IES consultadas, sendo que duas só aceitaram após a garantia de anonimato. Para manter o sigilo definido para essa pesquisa, essas instituições serão identificadas da seguinte forma: as de categoria privada serão nominadas como PR1 e PR2 e as de categoria pública, como PU1 e PU2. Na realização da entrevista, o coordenador da PR1 respondeu às perguntas da entrevista por escrito. Na coleta de dados com o questionário na PU2 e na PR1, houve um importante envolvimento dos coordenadores. O detalhamento da metodologia é apresentado na análise de resultados, apresentados a seguir.

\section{Apresentação e Análise dos Resultados}

A seguir, são apresentados e discutidos os resultados obtidos com os instrumentos de coleta de dados: analise documental dos instrumentos de avaliação de cursos utilizados pelo MEC; entrevistas realizadas com coordenadores dos cursos; e questionário aplicados aos docentes.

\subsection{Objetivo Específico 1: analisar como o Ministério da Educação supervisiona a implantação da PNEA no curso de graduação em Administração}

$\mathrm{Na}$ análise do Instrumento de Avaliação de Cursos de Graduação (IACG) e do Instrumento de Avaliação para Renovação de Reconhecimento de Cursos de Graduação (IARC), procurou-se identificar na Categoria de Avaliação Requisitos Legais e Normativos se a PNEA faz parte dos itens regulatórios. Como o MEC supervisiona a utilização das temáticas sobre sustentabilidade como tema transversal no curso foi feito por meio da análise da dimensão organização didático-pedagógica.

Na verificação dos itens que compõem os Requisitos Legais e Normativos, foram encontrados itens das Diretrizes Curriculares Nacionais (BRASIL, 2005). Os itens que compõem essa categoria são interpretados, nos dois instrumentos, como itens de atendimento obrigatório pela IES. Mas a PNEA (BRASIL, 1999; 2002) não é mencionada nessa categoria em nenhum dos instrumentos analisados. O desenvolvimento do tema sustentabilidade como um tema transversal é cobrado da IES, apesar de esse tema não estar expresso nas DCN do curso de Administração. Os temas transversais são categorizados como opcionais (BRASIL, 2005, art. 
$\left.5^{\circ}\right)$. Percebe-se que a exigência da sustentabilidade como tema transversal, expressa nesse indicador, não tem relação com a PNEA (BRASIL, 1999; 2002). A PNEA não está contextualizada nos instrumentos, verificando-se que o MEC não leva em conta a existência dessa política ao autorizar/fiscalizar o funcionamento do curso na IES. Percebe-se a ausência de um ambiente legalmente estruturado, que se relacione com a PNEA, característica do isomorfismo coercitivo. (DIMAGGIO; POWELL, 2005; AGUIAR, 2007)

\subsection{Objetivo Específico 2: analisar como a IES incorpora conteúdos relacionados às temáticas sobre sustentabilidade no curso de graduação em Administração}

O alcance do objetivo específico foi possível com a análise dos Projetos Pedagógicos dos Cursos (PPC), com a entrevista realizada com os coordenadores $e$ algumas questões do questionário aplicado aos docentes. A PR1 e a PU2 negaram o acesso ao PPC, as PU1 e PR2 deram acesso parcial. A análise dos PPCs das PR2 e PU1 permitiu a identificação da utilização de trabalhos interdisciplinares. No caso da PU2, esse trabalho tem estreita ligação com três disciplinas que desenvolvem temáticas sobre sustentabilidade no curso. O documento da PR2 menciona um seminário no segundo semestre do curso, que apresenta casos pesquisados pelos alunos com foco em sustentabilidade, palestras sobre temáticas relacionadas e duas disciplinas sobre sustentabilidade. Por meio da análise dos documentos disponibilizados, foram identificadas duas metodologias para aplicação de um tema transversal: Projeto Interdisciplinar (PI), trabalho que pode ser desenvolvido no curso utilizando a contribuição de diversas disciplinas; $e$ as Disciplinas, as Palestras e as Assessorias (DPA) por meio da utilização de disciplina que desenvolve temáticas sobre sustentabilidade no curso e/ou um evento realizado com foco em casos sobre sustentabilidade e apresentação de palestras. (ARAÚJO, 2003b)

$\mathrm{Na}$ entrevista com os coordenadores, ao serem questionados sobre como as temáticas sobre sustentabilidade são ministradas no curso e nas disciplinas, foram obtidas as seguintes informações: o coordenador da PR1(IES que não permitiu acesso ao PPC) informou que as ementas das disciplinas são planejadas de forma que os conteúdos ministrados sejam associados trans- versalmente com a temática sobre sustentabilidade, sem destacar a metodologia. Tomou-se a iniciativa de pesquisar no site da IES a grade curricular oferecida no curso e verifica-se que é oferecida uma disciplina no curso.

Os coordenadores da PR2 e da PU1 declaram que além do trabalho interdisciplinar os professores tem a liberdade de utilizar outras formas metodológicas. $\mathrm{O}$ coordenador da PU1 declarou que o curso se apoia fortemente na formação profissional dos professores. $\mathrm{O}$ coordenador da PR2 informou que o curso é composto de duas disciplinas que desenvolvem temáticas sobre sustentabilidade. O coordenador da PU2 informou que o curso se utiliza de uma disciplina anual. Essas iniciativas estão em discordância com a PNEA, que impede que o curso utilize uma disciplina para aplicar esse tema transversal (BRASIL, 1999, art. 10). O coordenador da PU2 mencionou trabalhos solicitados por algumas disciplinas, que utilizam a contribuição do conteúdo ministrado nas disciplinas anuais sobre sustentabilidade. Confirmam-se nas entrevistas as metodologias PI e DPA, a resposta do coordenador da PR1 acrescenta a metodologia TID o Tema Transversal Incorporado na Disciplina (ARAÚJO, 2003b). A integração de temáticas sobre sustentabilidade nas disciplinas descritas pelo coordenador da PR1 e as respostas dos coordenadores das PR2 e PU1, indicam a importância da atuação dos docentes e apontam para a possibilidade de identificação de outras metodologias no questionário dos professores.

Responderam o questionário 114 docentes, sendo que, nove docentes da PR1, 31 da PR2, 34 da PU1 e 40 da PU2. Ao serem questionados se a IES inseriu temáticas sobre sustentabilidade como tema transversal na disciplina: 62 (54.4\%) dos docentes responderam que a IES não inseriu as temáticas nas disciplinas que ministra; 18 (15.8\%) responderam que a IES inseriu as temáticas em todas as disciplinas; e 34 (29.8\%) em uma ou duas das disciplinas que ministra.

$\mathrm{O}$ alto percentual de docentes que responderam que a IES não inseriu as temáticas nas suas disciplinas está em concordância com as respostas dos coordenadores. Apenas o coordenador da PR1 afirmou que as temáticas estão inseridas nas disciplinas do curso. Ao assinalarem as metodologias utilizadas para abordar a(s) temática(s), os docentes indicaram uma, duas ou três metodologias: 27 indicam a metodologia TID - 
temática está integrada intrinsecamente ao conteúdo da disciplina; 34 Atividades Pontuais (AP) - trabalhos, módulos, aulas e/ou atividades específicas na disciplina; dos 29 que indicaram a DPA - como uma disciplina específica, 21 apontaram um evento (palestra ou seminário); e 25 indicaram a PI - Atividade que envolve um trabalho coordenado entre as disciplinas. O Projeto Interdisciplinar (PI) e a Disciplina foram mencionados pelos coordenadores (PU1 e PR2).

Verificou-se que as IES pesquisadas incorporam conteúdos relacionados às temáticas sobre sustentabilidade como tema transversal no curso utilizando as seguintes metodologias levantadas por Araújo (2003b): PI - Projeto Interdisciplinar; DPA - Disciplina, Palestra e Assessoria - na forma de uma disciplina e de um evento; AP - Atividades Pontuais; e TID - Tema Transversal Incorporado na Disciplina.

\subsection{Objetivo Específico 3: identificar quais pressões isomórficas motivaram a inserção da temática sobre sustentabilidade no curso}

Algumas perguntas da entrevista com os coordenadores e do questionário aplicado aos docentes, foram importantes para o alcance deste objetivo. Para a questão "Como a IES se motivou a inserir as temáticas sobre sustentabilidade no curso?" os coordenadores das IES privadas informaram que a demanda do MEC deu o primeiro impulso para essa iniciativa, mas houve uma continuidade da discussão e a ação foi ampliada para além das exigências. O coordenador da PU1 informou que a motivação para a inclusão das temáticas veio das exigências sociais, que impunham uma formação mais ampla para o administrador. As expectativas sociais podem exercer pressões formais e informais, que levam a organização a uma conformidade (DIMAGGIO; POWELL, 2005), gerando um isomorfismo coercitivo, sem ligação a uma exigência legal. O coordenador da PU2 informou que a reformulação do PPC, em 2009, guando já era coordenador, foram decisivas. Percebe-se que a experiência profissional desse coordenador, como docente e pesquisador, foi um forte motivador para o uso das temáticas sobre sustentabilidade no curso.
Na questão "Como a ação do MEC foi importante para o uso das temáticas sobre sustentabilidades no curso?" o coordenador da PR1 respondeu que o MEC foi importante por ter dado o impulso inicial. O coordenador da PR2 respondeu que esta ação motivou a IES a pesquisar sobre o tema.

Para a questão "Como a ação do MEC foi importante para a escolha da forma de transversalidade utilizada para desenvolver a temática no curso?" Os coordenadores da PR1 e da PU1 responderam que a ação do MEC teve uma baixa importância e que o envolvimento dos professores de diferentes áreas/ cursos foi preponderante. Os modos de interpretar a realidade aliada à experiência profissional tem forte influência nas decisões tomadas dentro da organização (DIMAGGIO; POWELL, 2005). Finalmente, o coordenador da PU2 aponta a combinação das disciplinas sobre sustentabilidade e os trabalhos interdisciplinares como preponderantes.

Ao serem perguntados se os professores já haviam proposto o uso de temáticas sobre sustentabilidade na disciplina, os coordenadores da PRI e PR2 responderam que sim e os coordenadores das PU1 e PU2 responderam que não. Nas entrevistas foi possível identificar a presença do isomorfismo normativo atuando para a inserção da temática sobre sustentabilidade no curso. Isso se dá pela experiência profissional do coordenador da PU2 que atuou fortemente na reformulação do PPC, no envolvimento dos professores na escolha da metodologia para inserção da temática sobre sustentabilidade nas duas IES privadas e a forma com a PU1 se apoia na formação inicial dos seus docentes.

O isomorfismo coercitivo se destacou pela pressão social para a formação do administrador. A pressão provocada pelo MEC teve menos impacto. A exigência legal do MEC e o conhecimento sobre a PNEA, que deveriam criar um ambiente legal que obrigasse as organizações a se moldarem (DIMAGGIO; POWELL, 2005; VENARD; HANAFI, 2008), não se destacou como uma pressão isomórfica coercitiva. Não foi percebida a atuação do isomorfismo mimético. 


\subsection{Objetivo Específico 4: verificar se a formação inicial do docente é geradora de pressão normativa ao contemplar temas relacionados à sustentabilidade, EA ou tema transversal}

O alcance desse objetivo utilizou as perguntas entrevista e do questionário. Somando um total de 118 pesquisados - 114 docentes e quatro coordenadores. Quanto à titulação, dos 118 pesquisados, $51,7 \%$ (61) deles são doutores; 39 (33\%) mestres e são especialistas 18(15\%). A PNEA determina que a dimensão ambiental deve constar do currículo de formação de professores de todos os níveis e em todas as disciplinas (BRASIL, 1999), sendo permitida aos cursos de Pós-Graduação a possibilidade de se utilizar de disciplina específica. Foi perguntado aos docentes e aos coordenadores se no curso de titulação havia disciplina que abordava temáticas sobre sustentabilidade, incluindo EA, metodologias e sustentabilidade com tema transversal. Nessas questões, a maior parte dos profissionais respondeu que no curso de titulação não havia disciplinas que abordavam: as temáticas sobre sustentabilidade (83); sobre EA (95); metodologias para aplicação de um tema transversal (78); e para aplicar a sustentabilidade como tema transversal (98).

O processo de formação inicial auxilia o docente a abordar problemas transdisciplinares e integrar distintos campos, além de criar processos de unificação (CARVALHO, 2003). A educação formal gera a legitimação a partir de uma base comum nos profissionais. As universidades $e$ as instituições de treinamento $e$ formação profissional constituem importantes centros de desenvolvimento de normas entre os profissionais. (DIMAGGIO; POWELL, 2005)

No questionário dos professores realizou-se o cruzamento entre as questões - "Você aborda temáticas sobre sustentabilidade ao ministrar sua aula?" Nesse cruzamento, é possível verificar, entre os professores que abordam as temáticas sobre sustentabilidade ao ministrarem sua aula, todos ou a maior parte deles tiveram em sua formação inicial disciplinas que abordavam sustentabilidade, EA, metodologias para aplicar a um tema transversal ou metodologias para aplicar a sustentabilidade como tema transversal.

\begin{tabular}{|c|c|c|c|c|c|c|}
\hline & & & \multicolumn{4}{|c|}{$\begin{array}{l}\text { Você aborda } \\
\text { temáticas sobre } \\
\text { sustentabilidade ao } \\
\text { ministrar sua aula? }\end{array}$} \\
\hline \multirow{2}{*}{\multicolumn{3}{|c|}{$\begin{array}{l}\text { Tiveram, na formação inicial, } \\
\text { disciplinas que abordavam: }\end{array}$}} & Sim & $\%$ & Não & $\%$ \\
\hline & & & 70 & 61.4 & 44 & 38.6 \\
\hline \multirow{2}{*}{$\begin{array}{l}\text { Temáticas sobre } \\
\text { Sustentabilidade }\end{array}$} & $\operatorname{Sim}$ & 31 & 18 & 25.7 & 13 & 27.3 \\
\hline & Não & 83 & 52 & 74.3 & 31 & 72.7 \\
\hline \multirow{2}{*}{ Temáticas sobre EA } & Sim & 19 & 9 & 12.6 & 10 & 15,9 \\
\hline & Não & 95 & 61 & 87.4 & 34 & 84.1 \\
\hline \multirow{2}{*}{$\begin{array}{l}\text { Metodologia para } \\
\text { aplicar qualquer } \\
\text { tema transversal }\end{array}$} & Sim & 36 & 28 & 40.0 & 8 & 15,9 \\
\hline & Não & 78 & 42 & 60.0 & 36 & 84.1 \\
\hline \multirow{2}{*}{$\begin{array}{l}\text { Metodologia para aplicar } \\
\text { a sustentabilidade como } \\
\text { tema Transversal }\end{array}$} & Sim & 16 & 11 & 18.6 & 5 & 11.4 \\
\hline & Não & 98 & 59 & 81.4 & 39 & 88.6 \\
\hline
\end{tabular}

Quadro 3: Cruzamento de Perguntas

Fonte: Quadro elaborado pelos autores a partir das respostas colhidas nos questionários

Os porcentuais de professores que tiveram durante sua formação inicial as disciplinas relacionadas com a sustentabilidade, EA e as metodologias para aplicação de um tema transversal são parecidos entre os docentes que usam e não usam temáticas sobre sustentabilidade ao ministrar a sua disciplina.

A presença do Isomorfismo Normativo gerado pela formação inicial do docente não se confirma. Isto decorre da observação de que não existe relação significativa entre os professores que responderam que usam as temáticas sobre sustentabilidade na sua disciplina e sua formação ter contemplado temas relacionados à sustentabilidade, EA ou tema transversal.

\subsection{Objetivo Específico 5: verificar se os docentes foram capacitados para realizar a inserção das temáticas sobre sustentabilidade ao ministrarem a disciplina e identificar os responsáveis por essa formação}

A capacitação do profissional é um processo concomitante ao exercício profissional (GARCIA, 1992), pois desenvolve novas formas didáticas e auxilia o professor a repensar questóes de ensino que utiliza na sala de aula (TRIVELATO, 2003). Na entrevista com os coordenado- 
res, ao serem indagados sobre como os docentes foram capacitados para desenvolverem as temáticas sobre sustentabilidade como tema transversal na disciplina, os coordenadores das PU1 e PU2 e PR2 informaram que a IES não realiza esse tipo de capacitação. O coordenador da PU1 acrescentou que a instituição tem total confiança na formação inicial dos seus professores e não ministra cursos de doutrinação para os docentes utilizarem as metodologias para um tema transversal.

O coordenador da PR1 respondeu que a IES realiza uma formação interna, por meio de um curso de extensão, para capacitar seus docentes a tratarem as temáticas sobre sustentabilidade como tema transversal. Dos 114 pesquisados, 44,7\% (51) recebeu algum tipo de capacitação/atualização profissional na IES que atua ou em outra IES. Ao serem questionados se a IES ministra/oferece cursos de formação continuada para o docente: 63 (55.3\%), docentes responderam que não. Dos 45 que responderam sim, 24 tiveram também uma capacitação para aplicar um tema transversal.

\subsection{Objetivo Específico 6: analisar quais metodologias e quais temas os professores utilizam para a inserção das temáticas sobre sustentabilidade como tema transversal ao ministrarem a disciplina}

O alcance desse objetivo específico foi possível por meio das questões do questionário aplicado aos docentes. Dos 114 professores pesquisados, 44 docentes responderam que não abordam as temáticas sobre sustentabilidade na disciplina e 70 deles abordam. No Quadro 4 apresentam-se as respostas para a questão "Como aborda a(s) temática(s) sobre sustentabilidade ao ministrar a disciplina?"

\begin{tabular}{|l|c|c|c|c|}
\hline & PR1 & PR2 & PU1 & PU2 \\
\hline Total de Docentes & 9 & 31 & 32 & 40 \\
\hline $\begin{array}{l}\text { Nos momentos em que seja conveniente } \\
\text { tocar no assunto e passar sua visão sobre } \\
\text { o tema - TCO }\end{array}$ & 1 & 5 & 12 & 11 \\
\hline $\begin{array}{l}\text { A temática esta integrada intrinsecamente } \\
\text { ao conteúdo da Disciplina - TID }\end{array}$ & 12 & 8 & 11 & 10 \\
\hline $\begin{array}{l}\text { Utilizando atividades pontuais - } \\
\text { trabalhos, módulos, aulas e/ou atividades } \\
\text { especificas - AP }\end{array}$ & 2 & 5 & 9 & 8 \\
\hline
\end{tabular}

Quadro 4: Metodologias Utilizadas pelos Docentes

Fonte: Quadro elaborado pelos autores a partir das respostas colhidas nos questionários
As metodologias TID - Tema Transversal Incorporado na Disciplina e AP - Atividade Pontual já haviam sido ditadas pelos docentes como metodologias utilizadas para a inserção das temáticas no curso. Foi acrescentada a metodologia TCO - Tema Transversal como Currículo Oculto. A metodologia TCO tem como característica o fato de não ter um registro ou monitoramento por parte da instituição de ensino (ARAÚJO, 2003b). É o professor quem decide o momento e o tema que deve ser passado aos alunos. As escolhas podem não contemplar os objetivos do curso para a formação do discente.

O cruzamento de todas as respostas sim (70) para "Você aborda temáticas sobre sustentabilidade ao ministrar sua aula?" com "Quais disciplinas ministra no curso de graduação em Administração atualmente?" e "Quais temáticas sobre sustentabilidade são abordadas em suas aulas?" tornou possível relacionar as temáticas sobre sustentabilidade, utilizadas pelos professores ao ministrarem as disciplinas (Quadro 5). Para uma uniformização das respostas, já que cada IES nomeia o mesmo conteúdo didático de forma diferente, identifica-se cada disciplina citada conforme o Quadro 2 que apresenta a uma proposta para desenvolver transversalmente temáticas sobre sustentabilidade.

No Quadro 5 percebe-se que muitas das temáticas que compõem a proposta adaptada a partir de Souza et al. (2011a; 2011b) e Barbieri e Silva (2010; 2011) têm reflexo no levantamento realizado a partir da resposta dos professores. Observa-se a necessidade de uma maior diversificação nas temáticas utilizadas. Verifica-se o uso de termos muito genéricos, tais como Sustentabilidade Econômica e Social/Desenvolvimento Sustentável, ou pouco abrangentes, como Reciclagem e Projetos Sociais, Balanço Social e ISE Bovespa, TI Verde e Lixo Eletrônico.

No caso das IES - PR2, PU1 e PU2 que disseram não integrarem temáticas sobre sustentabilidade na disciplina e os docentes tem a liberdade de escolher as temáticas que lhes convém para inserir na disciplina. Araújo (2003b) indica que se evite essa situação, pois a escolha do docente pode não contemplar a necessidade do curso/disciplina. Uma capacitação profissional (GARCIA, 1992; TRIVELATO, 2003) poderia atualizar os docentes quanto às temáticas sobre sustentabilidade aderente às disciplinas que ministram. 


\begin{tabular}{|c|c|}
\hline $\begin{array}{l}\text { QUAIS DISCIPLINAS } \\
\text { SÃO MINISTRADAS NO } \\
\text { CURSO ATUALMENTE? }\end{array}$ & $\begin{array}{c}\text { QUAIS TEMÁTICAS SOBRE SUSTENTA- } \\
\text { BILIDADE SÃO ABORDADAS EM SUAS } \\
\text { AULAS? }\end{array}$ \\
\hline $\begin{array}{l}\text { Administração } \\
\text { financeira } \\
\text { e Orçamentária }\end{array}$ & $\begin{array}{l}\text { ISO 1400; Sustentabilidade } \\
\text { econômica e ambiental; } \\
\text { Sustentabilidade dos ecossistemas } \\
\text { e das empresas; Indicadores de } \\
\text { sustentabilidade; Balanço social; } \\
\text { Globalização e Meio ambiente. }\end{array}$ \\
\hline $\begin{array}{l}\text { Teorias da } \\
\text { Administração e } \\
\text { das organizações } \\
\text { Administração } \\
\text { estratégica } \\
\text { Administração de } \\
\text { sistema de informação }\end{array}$ & $\begin{array}{l}\text { Questões climáticas e } \\
\text { Mobilidade urbana; } \\
\text { Responsabilidade social; ISE- } \\
\text { Bovespa; Ética empresarial; } \\
\text { Gestão de Stakeholders; } \\
\text { Produção mais limpa; } \\
\text { Desenvolvimento sustentável; } \\
\text { Sustentabilidade econômica e social; } \\
\text { Lixo tecnológico e TI verde; } \\
\text { Análise do ciclo de vida. }\end{array}$ \\
\hline $\begin{array}{l}\text { Administração de } \\
\text { Recursos Humanos }\end{array}$ & $\begin{array}{l}\text { Sustentabilidade social e econômica; } \\
\text { Desenvolvimento sustentável; } \\
\text { Ecoeficiência; Responsabilidade social; } \\
\text { Reciclagem e Projetos sociais; Gestão } \\
\text { para o desenvolvimento sustentável. }\end{array}$ \\
\hline $\begin{array}{l}\text { Administração } \\
\text { de Materiais, de } \\
\text { Produção e Logística }\end{array}$ & $\begin{array}{l}\text { Competitividade X sustentabilidade; } \\
\text { Produção mais limpa; } \\
\text { Localização empresarial; } \\
\text { Logística reversa; } \\
\text { Sustentabilidade da logística; } \\
\text { Responsabilidade social ambiental; } \\
\text { Projetos de sistemas de produção; } \\
\text { Ecoeficiência; Reciclagem; } \\
\text { Análise do ciclo de vida; Ergonomia; } \\
\text { Competitividade x sustentabilidade. }\end{array}$ \\
\hline $\begin{array}{l}\text { Administração } \\
\text { mercadológica/ } \\
\text { marketing }\end{array}$ & $\begin{array}{l}\text { Consumo consciente; } \\
\text { Obsolência planejada; } \\
\text { Consumo verde e Marketing social; } \\
\text { Responsabilidade social do marketing; } \\
\text { Consumo sustentável; Sustentabilidade } \\
\text { como Vantagem competitiva. }\end{array}$ \\
\hline
\end{tabular}

Quadro 5: Temáticas Sobre Sustentabilidade Abordadas nas Disciplinas

Fonte: Quadro elaborado pelos autores a partir das respostas colhidas nos questionários

\subsection{Resposta às Questões Básicas de Pesquisa}

$\mathrm{O}$ desenvolvimento desta pesquisa se norteou por responder a duas questões básicas e envolveu a elaboração de seis objetivos de específicos. A análise dos resultados alcançados é desdobrada para avaliar as questões centrais de pesquisa: Quais são as pressões que contribuem para a institucionalização da Educação
Ambiental em cursos de graduação em Administração como tema transversal? E existem pressões isomórficas que poderiam facilitar a convergência e a articulação do ensino ambiental como tema transversal? Pelos resultados pode-se concluir que, nas IES pesquisadas, a pressão isomórfica coercitiva, por parte da sociedade, e normativa, ligada à atuação profissional, são as que mais contribuem para a institucionalização da Educação Ambiental em cursos de graduação em Administração como tema transversal.

A pressão coercitiva exercida pelo MEC foi identificada como branda, sem sintonia com as determinações da PNEA. O que realmente leva a IES a utilizar as temáticas sobre sustentabilidade no curso de Administração são as exigências sociais para formação do administrador. Verificou-se, também, que a PNEA não permite a realização de uma disciplina sobre sustentabilidade no curso, fato observado na maioria das IES pesquisadas. Uma atuação coercitiva do MEC, sintonizada com as determinações da PNEA em instituir a transversalidade na disciplina e, principalmente, uma pressão normativa provocada por uma formação inicial adequada e por cursos de capacitação que disseminassem a importância, a metodologia e as temáticas relacionadas a cada disciplina, facilitariam a convergência e a articulação do ensino ambiental como tema transversal no curso de graduação em Administração.

\section{Considerações e Proposições Finais}

O trabalho apresentado se contextualiza a partir do cenário traçado pela PNEA que determina a inclusão da EA em todos os níveis do ensino brasileiro, de modo transversal, continuo e permanente, vedando às instituições de ensino sua utilização como uma disciplina específica. A falta de sintonia da PNEA com as DCN da Administração é a conclusão mais geral e importante desta pesquisa, que justifica a abordagem deste tema como objeto de investigação, o que tem sido ignorado na academia da área de Administração sobre a EA para a formação do profissional de graduação.

De acordo com os resultados obtidos, verifica-se que o Ministério da Educação, ao supervisionar as IES, não considera a existência da PNEA. Esse é um resultado forte, mas inegável. Outras pesquisas 
poderiam identificar se essa postura que leva o MEC a ignorar, em seus documentos, as diretrizes traçadas pela PNEA, se faz presente na formação/treinamento dos profissionais da educação que atuam nas equipes fiscalizadoras formadas pelo MEC.

Ainda de acordo com a análise dos resultados, foram formuladas três proposições, que poderiam ser utilizadas em pesquisas futuras, que abrangessem um universo maior de IES que ofereçam cursos, presenciais ou a distancia, de graduação em Administração.

Na comparação das temáticas sobre sustentabilidade, utilizadas pelos professores e a proposta de preenchimento da linha de transversalidade (Quadro 2 ), verifica-se que múltiplos aspectos da sustentabilidade são desenvolvidos na área de Administração. Verificou-se, em alguns casos, a necessidade de adequação quanto à temática utilizada em função do conteúdo das disciplinas específicas, como finanças, marketing, recursos humanos, entre outras. Esses dados permitem elaborar a seguinte proposição: a EA como tema transversal de graduação em Administração segue o enfoque da sustentabilidade em seus múltiplos aspectos, de acordo com a dinâmica de geração do conhecimento das pesquisas da área.

O MEC dá um impulso inicial ao exigir que as temáticas sobre sustentabilidade sejam tratadas no curso de forma transversal, mas se contenta com uma utilização minimalista das temáticas, sem utilizar a PNEA como ferramenta para exigir/guiar uma utilização mais profunda $e$ incisiva e sem disseminar o conhecimento sobre a PNEA entre as IES. Com essa conclusão formula-se a segunda proposição: o MEC é o responsável pela a inserção do ensino transversal de EA do curso de Administração, mas por não exercer uma pressão isomórfica coercitiva (poder de autorizar e fiscalizar o curso) visando fazer cumprir as recomendações da PNEA, sendo sua atuação limitada a verificar se o ensino transversal é realizado ou não.

Conforme o levantamento realizado, as IES têm disciplinas que não utilizam as temáticas sobre sustentabilidade transversalmente. Algumas utilizam uma disciplina para ministrar a temática no curso, recurso vedado pela PNEA. Verificsa-se que as metodologias, para utilização de um tema transversal, são desconhecidas pelos coordenadores e que sua utilização depende da formação anterior dos docentes, em sua grande maioria sem a preparação adequada.
Diante dessa constatação a seguinte proposição é apresentada: as IES inserem no curso de graduação em Administração o ensino da sustentabilidade como uma resposta à ação coercitivas do MEC, mas sem integrar a temática transversalmente na totalidade das disciplinas, sem treinar docentes ou preparar metodologias e ações pedagógicas que vão ao encontro do exigido na PNEA. Já que todas as metodologias de aplicação de um tema transversal podem ser utilizadas concomitantemente, nada impede a existência de uma disciplina específica que o discuta mais amplamente em um curso de Graduação.

\section{REFERÊNCIAS}

AMBONI, N. et al. Interdisciplinaridade e complexidade no curso de graduação em Administração. In: ENCONTRO DA ASSOCIAÇÃO NACIONAL DE PESQUISA EM ADMINISTRAÇÃO, 34, 2010, Rio de Janeiro. Anais Eletrônicos... Rio de Janeiro: ANPAD, 2010. 1 CD-ROM.

ARAÚJO, U. F. Apresentação à edição brasileira. In: BUSQUET, M. D. et al. (Org.). Temas transversais em educação: bases para uma formação integral. 6. ed. São Paulo: Ática. 2003a. p 9-17.

\section{Temas transversais e a estratégia de}

projetos. São Paulo: Moderna, 2003b.

ASHWORTH, R.; BOYNE, G.; DELBRIDGE, R. Escape

from the Iron Cage? Organizational Change and

Isomorphic Pressures in the Public Sector. Journal

Public Administration Research and Theory, Oxford, n. 19 v. 1, p. 165-187, 2009

BARBIERI, J. C. A Educação Ambiental e a gestão ambiental em curso de graduação em Administração: objetivos, desafios e propostas. Revista de

Administração Pública, São Paulo, n. 38, v. 6, p. 919946, nov.-dez. 2004.

BARBIERI, J. C.; SILVA, D. Educação Ambiental e Gestão ambiental na formação do administrador: uma visão do quadro regulatório. In: MORETTI, S. L. A.(Org.). Ensino e Pesquisa em Administração: propostas sobre a capacitação docente. São Paulo: Ottoni, 2010. 
BARBIERI, J. C.; SILVA, D. Educação Ambiental na formação do administrador. São Paulo: CengageLearning, 2011.

BERNARDES, M. B. J; PRIETRO É. C. Educação Ambiental: disciplina versus tema transversal. Revista eletrônica do Mestrado de EA - FURG, Rio Grande, v. 24, p. 173-185, jan.-jul. 2010.

BROUTHERS, L. E.; O'DONNELL, E.; HADJIMARCOU, J. Generic Product Strategies for Emerging Market Exports into Triad Nation Markets: A Mimetic Isomorphism Approach. Journal of Management Studies, Nova Jersey, n. 42, v. 1, jan. 2005.

BRASIL. Lei n. 9.795, de 25 de abril de 1999. Dispõe sobre a Educação Ambiental, institui a Política Nacional de Educação Ambiental e dá outras providências. Diário Oficial da União, Brasília, DF, 28 de abril de 1999. Disponível em: <http:/www.planalto.gov.br/ccivil_03/Leis/ L9795. htm>. Acesso: 11 jul. 2010.

BRASIL. Decreto 4.281, de 25 de junho de 2002. Regulamenta a Lei n. 9.795, de 27 de abril de 1999. Diário Oficial da União. Brasília, DF, 26 de junho de 2002. Disponível em: < http://www.planalto.gov.br/ ccivil_03/decreto/2002/d4281.htm>. Acesso em: 12 jul. 2010 .

BRASIL. Congresso Senado. Resolução n. 1, de 2 de fevereiro de 2004. Institui as Diretrizes Curriculares Nacionais do Curso de Graduação em Administração, Bacharelado. Diário Oficial da União. Brasília, DF, 4 de março de 2004, Seção 1, p. 11. Disponível em: $<$ http://portal.mec.gov.br/ cne/arquivos/pdf/rces01_04. pdf $>$. Acesso em: 24 ago. 2010.

CARVAlHO. A. M. P. (Coord.). Formação Continuada de Professores. São Paulo: Thompson, 2003, p. 1-15.

CORAIOLA, D. M.; MACHADO-DA-SILVA, C. L. Discurso organizacional e Isomorfismo institucional: As mudanças gráficas em jornais brasileiros. Revista Eletrônica de Ciência Administrativa, [on-line], Campo Largo-PR, v. 7, n. 2, p. 1-13, nov. 2008.

DIMAGGIO, P.; POWELL, W. A gaiola de ferro revisitada: isomorfismo institucional e racionalidade coletiva nos campos organizacionais. Revista de Administração de Empresas, Rio de janeiro, v. 45, n. 2, p. 74-86, 2005.
EISENHARDT, K. M. Building Theories From Case Study Research. Academy of Management. The Academy of Management Review, Briarcliff Manor-NY, v. 14, n. 4, 1989. p. 522-550.

FENNELL, M. L. The effects of environmental characteristics on the structure of hospital clusters.

Administrative Science Quarterly, Ithaca-NY, v. 25, p. 485-510, 1980.

FREITAS, C. A. S.; GUIMARÃES, T. A. Isomorphism, Institutionalization and Legitimacy: operational auditing at the court of auditors. Revista de Administração Contemporânea, Edição Especial, p. 153-175, 2007.

GARCIA, C. M. A formação de professores: novas perspectivas baseadas na investigação sobre o pensamento do professor. In: NÓVOA, A. (Org.). Os professores e sua formação. Lisboa: Publicações Dom Quixote, 1992.

GIMENEZ, F. A. P.; JÚNIOR, P. H. GRAVE, P. S. Isomorfismo mimético em estratégia: uma ferramenta para investigação. Revista de Administração Mackenzie , v. 8, n. 4, p. 35-59, 2007.

GIN, G. O.; SHEN, J. J.; MOSELEY, C. B. Community orientation and the strategic posture of hospitals. Research and Perspectives on Healthcare, v. 87, n. 3, 2009.

GONÇALVES-DIAS, S. L. F; TEODÓSIO, A. S. S; CARVALHO, S; SILVA, H. M. R. Consciência Ambiental: um estudo exploratório sobre suas implicações para o ensino de Administração. RAE - Eletrônica, [on-line], v. 8, n. 1, p. s/n, jan.-jun. 2009.

KLUGLIANSKAS, I. Ensino da gestão ambiental de Administradores de empresas: a experiencia da FEA/USP. In: ENCONTRO NACIONAL DE GESTÃO EMPRESARIAL E MEIO, 2, 1993, Anais, São Paulo, dez.1993, p. 151-160.

LACOMBE, B. M. B.; CHU, R. A. Políticas e práticas de gestão de pessoas: as abordagens estratégica e institucional. Revista de Administração de Empresas, v. 48, n. 1, jan.-mar. 2008.

MACHADO-DA-SILVA, C. L.; COSER, C. Rede de relações interorganizacionais no Campo organizacional de Videira, SC. Revista de Administração

Contemporânea, v. 10, n. 4, p. 09-45, out.-dez. 2006. 
MEC. Parâmetros Curriculares Nacionais: introdução aos parâmetros curriculares nacionais. Brasília: MEC/

SEF, 1997. Disponível em: < http://portal.mec.gov.br/seb/ arquivos/pdf/ livro01.pdf.> . Acesso em: 26 ago. 2010.

MENDONÇA, J. R. C.; AMANTINO-DE-ANDRADE, J. Gerenciamento de Impressões: em busca de legitimidade organizacional, Revista de Administração de

Empresas, v. 43, n. 1. p. 36-48, 2003.

MORENO, M. Temas transversais: um ensino voltado para o futuro. In: BUSQUET, M. D.; CAINZOS, M.; FERNÁNDEZ, T.; LEAL, A.; MORENO, M.; SASTRE, G. (Org.). Temas transversais em educação, 6. ed. São Paulo: Ática, 2003. p. 19-59.

NICOLESCU. B. O manifesto da

transdisciplinaridade. São Paulo: Triom, 1999.

ROSSETO, C. R.; ROSSETO, A. M. Teoria institucional e a dependência de recursos na adaptação organizacional. RAE - Eletrônica, [on-line], São Paulo, v. 4, n. 1, jan.jun. 2005.

SOUZA, M. T. S. et al. A pós-graduação estricto sensu em Administração como elemento de formação de pesquisadores na área ambiental. In: ENCONTRO DA ASSOCIAÇÃO NACIONAL DE PESQUISA EM ADMINISTRAÇÃO, 35, 2011. Anais Eletrônicos... Rio de Janeiro, setembro de 2011a. CD-ROM.

SOUZA, M. T. S. et al. Perfil e Evolução da Pesquisa em Sustentabilidade Ambiental: uma Análise Bibliométrica. In: ENCONTRO DA ASSOCIAÇÃO NACIONAL DE PESQUISA EM ADMINISTRAÇÃO, 35, 2011. Anais

Eletrônicos... Rio de Janeiro, setembro de 2011b. CDROM.

TOLBERT. P.; ZUCKER, L. A institucionalização da teoria institucional. In: CLEGG, S.; HARDY, C.; NORD, W.

Handbook de estudos organizacionais. São Paulo: Atlas, 1999.

TRIVELATO. S. L. F. Um programa de Ciências para educação Continuada. In: CARVALHO. A. M. P. (Coord.). Formação continuada de professores. São Paulo: Thompson, 2003. p. 63-85.
VERNAD, B.; HANAFI, M. Organizational Isomorphism and Corruption in Financial Institutions: Empirical Research in Emerging Countries. Journal of Business Ethics, New York, NY, n. 81, p. 481-498, springer, 2008.

WINTHER, J. R. C. Parecer técnico jurídico sobre a PNEA - Lei n. 9.795. In. Educação Ambiental Legal. Brasília, DF: MEC/SEF, 2002. Disponível em: < http:// portal.mec.gov.br/secad/arquivos/pdf/educacaoambiental/ ealegal.pdf $>$. Acesso em: 10 out. 2010.

YIN, R. K. Estudo de caso: planejamento e métodos. 4. ed. Porto Alegre: Bookman, 2010. 